Revista de la red interuniversitaria de estudios sobre las literaturas rioplatenses contemporáneas en Francia

$23 \mid 2021$

La vereda de enfrente. Cruces entre las literaturas argentina y chilena del siglo XX

\title{
Noticias de la literatura chilena en Buenos Aires
}

Nouvelles de la littérature chilienne à Buenos Aires

Chilean literature news in Buenos Aires

\section{Carlos Walker}

\section{OpenEdition}

\section{Journals}

Edición electrónica

URL: https://journals.openedition.org/lirico/11165

DOI: 10.4000/lirico.11165

ISSN: 2262-8339

Editor

Réseau interuniversitaire d'étude des littératures contemporaines du Río de la Plata

Referencia electrónica

Carlos Walker, «Noticias de la literatura chilena en Buenos Aires», Cuadernos LIRICO [En línea], 23

2021, Publicado el 09 diciembre 2021, consultado el 07 enero 2022. URL: http://

journals.openedition.org/lirico/11165; DOI: https://doi.org/10.4000/lirico.11165

Este documento fue generado automáticamente el 7 enero 2022.

\section{c) (i) $९$}

Cuadernos LIRICO está distribuido bajo una Licencia Creative Commons Atribución-NoComercialSinDerivar 4.0 Internacional. 


\title{
Noticias de la literatura chilena en Buenos Aires
}

\author{
Nouvelles de la littérature chilienne à Buenos Aires \\ Chilean literature news in Buenos Aires
}

Carlos Walker

\section{Revelar y editar}

1 En algún momento de agosto de 1969, Raúl Ruiz y Antonio Skármeta coinciden en Buenos Aires. El primero, con 28 años, había reunido los dólares necesarios para procesar su película en un laboratorio porteño. El segundo, también de 28 años, pasaba unos días en la ciudad para acompañar la publicación de su más reciente libro de cuentos, asumida por un importante sello local, Sudamericana. Las circunstancias que rodean esta coincidencia permitirán, a modo de introducción, delimitar el terreno de interés de lo que sigue.

2 Tres tristes tigres obtuvo en Locarno el Leopardo de Oro, que resultó ser un inmejorable espaldarazo para la proliferación de obras que Ruiz fue filmando y escribiendo durante los siguientes cuarenta años. En el mismo festival, valga la anécdota, se le dio a Invasión una mención especial del jurado, aquel mítico film de Hugo Santiago en cuyo guion habían colaborado Adolfo Bioy Casares y Jorge Luis Borges. Desnudo en el tejado, había obtenido el primer premio de Casa de las Américas en 1969, consolidando a su autor como una de las grandes promesas de la joven literatura latinoamericana. El jurado para la sección de libros de cuentos estuvo compuesto por Oscar Collazos, Carlos Droguett, Jean Fran co, Onelio Jorge Cardoso y Francisco Urondo. Sudamericana promocionó el libro en los semanarios y en la prensa porteña sin mencionar el galardón obtenido, aunque el dato se consignaba en la contratapa. Tal vez mencionar el premio no era, necesariamente, una buena publicidad, tal vez la editorial se confió a la eficacia del slogan elegido para el inserto publicitario con que se acompañaba la imagen del libro: "La mayor revelación 1969 en las letras latinoamericanas". A su retorno de Europa, Ruiz rememoraba su paso por el festival suizo: "Al comienzo los estudiantes 
estaban en contra de mí, pero bastó una cita de Mao para ganarlos"; la misma nota de Ercilla complementa esta descripción de la conferencia de prensa previa al estreno: "Le preguntaron en qué medida su película contribuía al proceso de liberación latinoamericano. - Ninguna", habría respondido el realizador (cit. en Cáceres 2019: 111). En tren de hacer una semblanza del novel escritor chileno, un periodista argentino inquiere a Skármeta por su filiación política, quien, sin el humor de Ruiz, clama detestar los partidos políticos, aunque de inmediato aclara que eso no lo aleja de las expectativas del pueblo para con un "auténtico escritor" ("Chilenos" 1969: 58)2 Primera plana, el semanario insigne de la masificación de la cultura argentina en la década del sesenta, publicó en dos entregas consecutivas el cuento "Una vuelta en el aire", a modo de adelanto del libro de relatos premiado. La presentación del texto incluye, en pocas líneas, una observación que es al mismo tiempo un estado de situación de la literatura chilena y un punto de vista sobre aquello que es uno de los principales objetos de interés del célebre semanario: "El entusiasmo, una colección de cuentos de Antonio Skármeta publicada por Zig-Zag en 1967, hizo suponer que la orfandad de grandes narradores en Chile no duraría ya demasiado tiempo. La obra posterior de Skármeta confirmó esa suposición" (“Textos” 1969: 60). La reseña de Desnudo en el tejado publicada en el semanario Análisis se cierra sin hacerle el quite a cierta veta grandilocuente del periodismo cultural: "Más allá de las modas de la literatura latinoamericana, Antonio Skármeta demuestra una vez más que los renovadores del lenguaje, los adelantados están en esta parte del planeta" ("La sumisión" 1969: 73). La nota de Confirmado, donde Agustín Mahieu comenta el reconocimiento europeo obtenido por el film de Ruiz, arriesga un salto sobre el futuro del director a partir del que por entonces era su único largometraje exhibido: “Toda la estructura del film anuncia un tipo de cine que recién ahora despunta en un horizonte que pone en cuestión todas las reglas. [...] parece indudable que su entrada en el mundo internacional despertará discusiones; tal vez llega un nuevo estilo, un autor fuera de serie" (1969: 67).

3 En suma, dos jóvenes chilenos coinciden en Buenos Aires a fines de los años sesenta. La ciudad les ofrece soportes materiales que les permiten, a cada uno en su elemento, mostrar el estado de forma de sus propuestas estéticas. Más aun, los medios escritos que se ocuparon del film y del libro se apuran a ponderar la novedad que representaban sus expresiones para el campo cultural que los recibía a orillas del Plata. Valga el matiz, la novedad venía esta vez refrendada por el sistema de consagración y publicidad puesto en marcha por los premios internacionales. La juventud de ambos, sea dicho de paso, también es un asunto a considerar cuando se trata de aproximarse a la recepción de la que eran objeto las producciones cinematográficas y literarias del subcontinente.

De todas formas, estas circunstancias antes que apresurar conclusiones sobre el campo cultural argentino de fines de los años sesenta, permiten plantear las preguntas que están en la base de lo que desarrollaré a continuación ${ }^{3}$. En primer lugar, llevado por un interés documental, en lo que sigue presentaré una visión panorámica de la circulación de la literatura chilena en Buenos Aires, a fines de la década del sesenta. En segundo lugar, la edición, la circulación y la recepción crítica de los textos pertenecientes a la tradición chilena que se pude verificar en los semanarios de información o en las revistas especializadas, constituyen una suerte de repertorio de manifestaciones heterogéneas que, y esta es la hipótesis principal de lo que sigue, nos permitirán entrever características específicas del campo literario argentino de ese período. De este modo, lo que se diga de los textos y nombres de la literatura chilena que circulaban 
en Buenos Aires en ese entonces, permitirá interrogar las características de la literatura argentina que por esa vía se ponen en juego. La recepción argentina de los textos chilenos, entonces, servirá menos para evaluar el conocimiento y la repercusión de las expresiones letradas del país vecino que para buscar establecer las modalidades de lectura que predominaban en Buenos Aires hacia 1969. Las noticias de la literatura chilena permitirán, en síntesis, desplegar características propias de la literatura argentina.

5 ¿Y si la Buenos Aires de 1969 fuera un punto de vista?, ¿y si ese punto de vista fuera más aprehensible cuando se trata de lecturas hechas sobre tradiciones literarias extranjeras, vecinas, cercanas, pero al fin y al cabo foráneas? Si se acepta la exageración de atribuirle a una ciudad un punto de vista, un modo de leer específico exageración que tomo prestada de un subrayado de Virginia Woolf sobre Londres (2021: 72)-, y si se sigue la conjetura de que los rasgos propios de una literatura nacional se expresan de modo más claro cuando se los confronta con un sistema literario nacional cercano, geográfica y lingüísticamente hablando, se comprenderá el vaivén sobre el que se asienta la indagación que sigue. De un lado, las características con que circula la literatura chilena en Buenos Aires dentro de un período específico. Del otro, y en una suerte de contraplano hecho sobre los mismos materiales, la atención puesta sobre las marcas enunciativas de la lectura, sobre esas marcas que prolongan a la literatura argentina como una máquina de leer, como un punto de vista.

6 Para desplegar esta interrogación he seleccionado algunos episodios, cuyas características permiten confeccionar un panorama sobre el interés con que era leída la literatura chilena en la Buenos Aires de 1969, sobre su circulación material, sobre las valoraciones positivas y negativas, en suma, sobre los efectos que suscitaba y las vías en que se manifestaba. Una antología de relatos, un libro prácticamente desconocido de un gran autor, una serie de valoraciones sobre algunas expresiones poéticas, y un libro de un joven autor constituyen los episodios que abordaré a continuación.

\section{País de antologías}

7 En diciembre de 1968 se terminan de imprimir las Crónicas de Chile en los Talleres gráficos Zlotopioro hermanos, en la ciudad de Buenos Aires, las que llegan a las librerías a principios de 1969. El libro viene a integrarse a la colección Crónicas de la editorial Jorge Álvarez. La breve duración de la editorial (1963-1969), su decidida apuesta por la renovación cultural, y esa suerte de cenáculo literario que sesionaba en su librería en el centro de Buenos Aires, han ido otorgándole a la historia del sello editorial cierto halo legendario, al tiempo que se ha asentado su comprensión como "el representante más emblemático de una nueva generación de editores" (De Diego 2019: $68)$.

8 La mencionada colección Crónicas, dirigida por Julia Constenla, está conformada por veintiún libros, de los cuales sólo cinco de ellos incluyen en el título el nombre de un país, tres corresponden a países latinoamericanos -Crónicas de España (1965), de Chile (1968), de Italia (1968), de Cuba (1969), de Paraguay (1969) ${ }^{4}$. También hubo entregas que apelaban a otro tipo de divisiones geopolíticas, por ejemplo, las Crónicas de Latinoamérica (1968), las Crónicas de Norteamérica (1967) o las Crónicas de Buenos Aires (1965). Y hubo otras que se conformaron a partir de temas puntuales, Crónicas de la burguesía (1965), Crónicas de la violencia (1965), Crónicas del sexo (1965). Fue precisamente esta colección la 
que le dio mayor visibilidad a la editorial; ya en 1968 el editor declaraba que se habían vendido unos 400.000 ejemplares de las Crónicas (De Diego 2019: 69).

Entonces, la editorial en la que Copi, Ricardo Piglia, Manuel Puig, Óscar Masotta, Juan José Saer, entre otros, publicaran algunas de sus primeras entregas, la editorial en donde Nicolás Rosa tradujera por primera vez al español un libro de Roland Barthes (Podlubne 2017: 900), publica Crónicas de Chile. Se trata de una selección de textos coordinada por Rodrigo Quijada, que se abre con una breve "Advertencia necesaria" del compilador, a la que le siguen dieciséis textos seleccionados para la ocasión. La "Advertencia..." que introduce la antología, junto al montaje con que se organiza y se titulan las distintas partes del libro, y algunas características puntuales de los textos y sus respectivos autores, nos servirán para examinar las modalidades de presentación con que el volumen es concebido en vistas de su circulación en el campo cultural argentino.

Poco es lo que pude recabar bajo las restricciones que impone el mundo covid sobre el compilador de Crónicas de Chile, Rodrigo Quijada, un escritor chileno prácticamente desconocido en nuestro presente. Pese a ello, es posible anotar algunas señas de su recorrido hasta ese entonces. Para la época en que se publica el libro en Jorge Álvarez, Quijada tiene 25 años, ha publicado dos novelas, una, prometedora y juvenil novela, Bajo un silencio (1963), otra, en coautoría con Rodrigo Baño, Tiempo de arañas (1967), que en 1968 había obtenido el Premio Municipal de Literatura de Santiago y que antes de su publicación había conseguido una mención en el Concurso Hispanoamericano de Novela Zig-Zag. Una de las pocas notas de prensa disponible en línea sobre esta novela hace una breve semblanza de los autores y alude a un tiempo incierto en el que Quijada habría vivido en Buenos Aires, oficiando como relacionador público de la ignota revista Orbe y como director de una revista especializada en sexología cuyo nombre no figura (Apir 1986). En síntesis, el compilador es el escritor más joven de los que figuran en Crónicas..., ha sido recientemente premiado en Chile por una novela escrita en coautoría y editada por una de las más prestigiosas casas editoriales chilenas, Zig-Zag, y ha pasado algún tiempo instalado en Buenos Aires. No sabemos cómo es que se establece el contacto con Jorge Álvarez. También pudo haber sido en Santiago, donde Jorge Álvarez viajó en 1967, en compañía de, entre otros, Rodolfo Walsh, con el secreto designio de tomar el control de la editorial Zig-Zag (García Lupo $2012 \mathrm{Web}$ ). A pesar de ello, los pocos rasgos señalados coinciden con el perfil de la editorial argentina, con la orientación que la transformó en un emblema de la renovación editorial, pues la elección del joven escritor casi desconocido, aunque poseedor de prometedores reconocimientos, está en sintonía con el afán precursor que caracterizó a Jorge Álvarez.

11 Por añadidura, las escasas líneas que componen la "Advertencia" de Quijada refrendan este compromiso con la novedad y la actualidad. De hecho, allí encontramos la reivindicación del gesto autoral del propio Quijada, quien de entrada señala que el libro está compuesto "según los textos literarios que al compilador le han parecido de mayor vigencia" (1968: 7), y unos párrafos después se apura, sin desdeñar la provocación, a aventurar que una de las garantías de "calidad" de Crónicas... reside en que no incluye ningún texto del compilador.

La idea de la selección, apunta Quijada, es "desarrollar una visión espiritual de Chile", en la que "la labor de los jóvenes" ha sido objeto de una "principalísima atención", y cuyo protagonismo se propone en contra del "peso de perseverantes fantasmas" literarios. A renglón seguido, vuelve a marcar una toma de posición explícita de los 
criterios que le han servido para componer el libro: "Ahora es un joven, Antonio Skármeta, el que inicia estas crónicas. Cárguese el hecho a un afán innovador" (Quijada 1968: 7).

13 En cuanto a la composición de la antología, es preciso señalar que la reivindicación de la juventud se verifica menos en las cifras -el promedio de edad de todos los colaboradores bordea los cuarenta años- que en la consolidación de la denominada generación del '50 como el tronco principal sobre el que se asienta la selección de textos. Entre los dieciséis autores seleccionados, cinco de ellos figuran en la célebre Antología del nuevo cuento chileno (1954) -Guillermo Blanco, Jorge Edwards, María Elena Gertner, Claudio Giaconi, Enrique Lihn-, y las únicas ausencias que el compilador justifica con nombre y apellido, ambas por no contar con material inédito, son las de dos reconocidos integrantes de dicha generación, Enrique Lafourcade y José Donoso ${ }^{5}$. Más allá de los límites impuestos por este grupo, Crónicas de Chile también incluye a otros autores que rondan las mismas edades de los ya mencionados (30-40 años): Antonio Avaria, Cristián Huneeus, Carlos Ossa, Carlos Santander, Jorge Teillier ${ }^{6}$. Los menores de treinta son tres: Antonio Skármeta, José Román y Rodrigo Baño, mientras que los escritores de reconocidas trayectorias también son tres: Guillermo Atias, Nicanor Parra y Manuel Rojas. En síntesis, la visión espiritual de Chile que se quiere entregar en estas páginas no se asienta tanto en una juventud que da sus primeros pasos en las letras, sino en una generación de recambio que para ese entonces llevaba más de una década disputando los lugares hegemónicos del campo literario chileno (Godoy 1998).

14 De todas formas, lo anterior no invalida "el afán innovador" que podría representar la selección de autores hecha por Quijada. Antes bien, invita a buscar complementos de esa novedad en los otros aspectos del libro, vale decir, en los autores elegidos, en la división y montaje del conjunto, en las características de los textos. Para cerrar este apartado entonces, algunas observaciones al respecto.

Dentro de esta apretada descripción de la antología narrativa Crónicas de Chile, vale la pena detenerse en aquellos autores que escapan a este conjunto conformado por una juventud ampliada, pues tanto sus textos como sus nombres establecen ciertas posiciones sobre la tradición literaria chilena y confirman, por otra vía, el afán de intervenir en el campo literario, ya sea mediante la reivindicación del gesto autoral del que Rodrigo Quijada, el compilador, hace aspavientos, ya sea gracias al imaginario cultural de renovación que conlleva el trabajo editorial encabezado por Jorge Álvarez.

De Nicanor Parra (1914-2018) -figura emblemática de la renovación de la poesía chilena desde Poemas \& Antipoemas (1954) en adelante- se rescata un relato, "Gato en el camino", que el antipoeta publicara en 1935 cuando tenía 21 años. Se trata de la primera publicación de Parra de la que se tiene noticia, también es uno de sus pocos textos en prosa, cuyas líneas condensan, en parte, el gusto por el humor, el absurdo y la ruptura que marcarían toda su literatura ${ }^{7}$. De Guillermo Atías (1917-1979) se incluye un cuento titulado "El caso de la calle Colonia", que había formado parte de su libro de cuentos Un día de luz (1959). El nombre de Atías evoca por contigüidad a la denominada generación del '38, donde cabe destacar su proximidad al grupo Mandrágora, sus colaboraciones en la revista Multitud y su inclusión en la celebérrima Antología del verdadero cuento en Chile de Miguel Serrano ${ }^{8}$. Pero también y sobre todo en el nombre de Atías resuena tanto la reivindicación que hiciera de su obra Claudio Giaconi en "Una experiencia literaria" (1958), uno de los ensayos emblemáticos de la generación del '50, 
como la apuesta de Atías por la literatura urbana en oposición directa al criollismo, vale decir, a la tradición de mayor peso en la narrativa chilena (Osses 2017: 181). Por último, el texto que se incluye de Manuel Rojas (1896-1973) -“Chile, país vivido”, publicado originalmente en El árbol siempre verde (1960)- es el único escrito que se presenta como un "fragmento" de su versión original, también es el único de carácter ensayístico en Crónicas de Chile. Rojas, el más longevo de los escritores antologados, asociado en los manuales de literatura a la generación del '27, es uno de los narradores más relevantes de la literatura chilena, en particular, de aquello que Cedomil Goic caracterizara como la novela contemporánea (1997: 147). Más allá del lugar central que en ese entonces ocupa Manuel Rojas dentro de la literatura chilena y latinoamericana, vale la pena destacar aquí que el texto elegido para la publicación argentina ya había sido incluido en otra importantísima antología, el Autorretrato de Chile (1957), dirigida por Nicomedes Guzmán, uno de los más ilustres representantes del realismo chileno. De algún modo, la evocación del Autorretrato... impuesta por el texto de Rojas entrega, a contrapelo, el detalle de un movimiento decisivo de las Crónicas: de los cincuenta y un escritores "definitivamente representativos" (Guzmán 1974: 19) de la literatura chilena seleccionados por Guzmán queda uno solo en el libro publicado por Jorge Álvarez. Más aun, el texto de Rojas es el único incluido en Crónicas... del que se presenta sólo un fragmento, y este gesto de cortar adquiere mayor significación si se considera que el texto original no supera las diez páginas (extensión análoga a buena parte de los textos incluidos en el compilado argentino). En definitiva, la presencia de estos autores digamos, los no-jóvenes de la antología- prolonga por otras vías el afán innovador con que se presenta el libro.

\section{Un ilustre desapercibido}

La Embajada de Israel en Chile, a sugerencia de la Sociedad de Escritores chilena, le hace llegar a Manuel Rojas una invitación para visitar Israel. Si bien Rojas sabía que estaba en una lista de posibles invitados no pensaba que sería el escritor elegido, pues apenas unos meses antes había presidido en Santiago la Conferencia Sudamericana de intelectuales sobre la situación de los judíos soviéticos ${ }^{9}$. Este encuentro había estado enfocado a denunciar la situación de los judíos en la Unión Soviética, y contó, entre otros, con la participación de José Revueltas, Enrique Espinoza, José Santos González Vera, Jorge Luis Borges. Aunque por cuestiones políticas dudó si debía aceptar la invitación, Rojas se decidió a ir para conocer de cerca la vida en los kibutz, a los que veía como "una realización en pequeño del sueño de tantos" (1969: 18), lo que lo lleva a declarar a continuación que nunca ha dejado atrás su formación socialista y anarquista.

Las circunstancias de ese viaje y las lecturas hechas sobre la situación de Israel, junto a las reflexiones a las que estas dieron lugar, son plasmadas por Manuel Rojas en Viaje al país de los profetas, un libro de unas noventa páginas publicado en Buenos Aires en septiembre de 1969 por Ediciones Zlotopioro.

De vuelta en Chile, Rojas concede una entrevista a la revista En Viaje, órgano de la Empresa de Ferrocarriles del Estado, donde enumera su itinerario. Después de Israel estuvo en Grecia, Francia y España, para finalmente pasar unos días en Buenos Aires (Fuenzalida 2012: 187) ${ }^{10}$. La frecuencia mensual de la revista hace suponer que ya en marzo el escritor estaba de regreso, por otro lado, al final de Viaje al país de los profetas Rojas consigna que lo terminó de escribirlo en Santiago, el 14 de mayo de 1969. 
20 Sin duda, en este recuento de fechas sobresale la velocidad con que el libro se imprime, y aquí cabría suponer que este breve intervalo entre el fin de la escritura y la edición responden, en buena medida, al renombre del autor a nivel continental. Con todo, el tema del libro y la editorial en que se publica ofrecen una explicación suplementaria para este intervalo. En este marco, se ha de considerar que las Ediciones Zlotopioro, cuyo nombre en la portada es protagónico, ofició muy rara vez como casa editorial, en cambio, sí tuvo un rol destacado en el escenario editorial del período -Tiempo Contemporáneo, Jorge Álvarez, Galerna, entre otras casas editoriales locales, y revistas como Los Libros y Nuevos Aires, imprimían sus publicaciones en los Talleres Gráficos Zlotopioro hermanos ${ }^{11}$.

21 Por su parte, las solapas del libro presentan a Rojas ante el eventual lector de solapas argentino. De entrada, se consigna su nacimiento en Buenos Aires y su filiación chilena, se anotan algunos títulos destacados, entre ellos su novela Mejor que el vino, cuya mención permite acotar lo siguiente: "A esta novela le da nombre un versículo del Cantar de los Cantares, pues Manuel Rojas ha sido un gran lector de la Biblia" (1969: s/p). Luego se consigna su relevancia dentro de la literatura chilena y latinoamericana, se detallan algunos de sus viajes -sobresale su visita a la URSS y una edición en ruso que alcanzó un tiraje de 100.000 ejemplares-, se menciona una antología en hebreo de sus narraciones $\mathrm{y}$, finalmente, se anuncian dos prontas ediciones argentinas que lo competen: una biografía a cargo de Enrique Espinoza, que saldrá por el CEAL, y una edición completa de sus cuentos que publicará Sudamericana ${ }^{12}$. Como cierre del texto que ocupa ambas solapas, se menciona la Conferencia santiaguina de 1968 a la que ya hicimos alusión, presidida por Rojas, junto con una lista de participantes encabezada por Borges.

De todos modos y a pesar del lugar central que en ese entonces tenía Rojas en la literatura chilena y del subcontinente, lo que es refrendado por las solapas de Viaje..., el libro no concita la atención de las secciones literarias de los semanarios, ni de los diarios, ni de las revistas especializadas. La única nota encontrada está en el semanario Confirmado, dentro de un recuadro de "Novedades" que ocupa la mitad inferior de una página, y donde se reseñan en muy pocas líneas cuatro libros de aparición reciente, entre los que figura $\mathrm{El} \mathrm{fiord}{ }^{13}$. El breve texto reitera varios de los datos incluidos en las solapas, también ubica a su autor como "uno de los más grandes novelistas de Chile y de Sudamérica", y agrega un juicio laudatorio sobre el libro en relación con la obra precedente: "está sin duda a la altura de los mejores títulos de su producción" (“Novedades" 1969: 22).

El gran novelista chileno, entonces, suscita escaso interés en la prensa literaria porteña, apenas le dedican algunas palabras de circunstancia. Esta situación contrasta de manera elocuente con la recepción de la que es objeto Desnudo en el tejado de Antonio Skármeta, profusamente reseñado en los medios escritos, tal y como veremos más adelante.

Si bien se podría atribuir este fenómeno de recepción a la temática del libro, arguyendo que narrar una visita oficial a Israel tiene de entrada una vocación discreta -y esto bien a pesar de la confusión que puede suscitar la existencia de temáticas discretas cuando de literatura se trata-, también es posible señalar que, justamente, esa temática le permite a su autor desplegar toda una reflexión sobre la actualidad de las disputas geopolíticas. Es más, a través del relato del viaje Rojas refrenda su posición política a expensas de su desconfianza ante el aparato estatal y de la concomitante utopía de un mundo sin 
Estado y sin dinero (1969: 14, 36), a la que le agrega una apuesta y una confianza en el destino de Israel y sus ideales comunitarios, y un llamado a la "izquierda limpia y moral" a pelear por el destino de Medio Oriente (91) ${ }^{14}$.

Por otro lado, y siguiendo con la atención puesta sobre la falta de interés, se puede evocar un episodio de Viaje... en el que Rojas detalla su paso por la Universidad Hebrea de Jerusalén. Una vez terminado el encuentro con los estudiantes de literatura hispanoamericana le informan que, al día siguiente, en el mismo contexto, se entrevistarán con Borges, quien también está de visita en el país (68). Esos mismos días, Rojas asiste a una recepción en el Instituto Central de Relaciones Culturales Israel Ibero América, España y Portugal. El evento está abarrotado de gente, y a poco de llegar, casi a los empujones, Rojas consigue salir de allí, no sin antes haber divisado a lo lejos a su colega trasandino: "hace un gran calor, me pregunto qué sentirá Borges, que veo ahí como si estuviera emparedado" (70). En resumen, dos de los más grandes narradores de sus respectivas literaturas nacionales, sino los más grandes, comparten un mismo evento en Israel hacia fines de los sesenta, pero ni siquiera se saludan. Rojas, que lo ve a lo lejos, no se acerca, y nadie produce el encuentro, ni siquiera sabemos si Borges habrá estado al tanto de la presencia de Rojas allí. Como sea, la indiferencia que hay entre ambos narradores es palmaria.

Ahora bien, ante la falta de interés con la que circula el libro de Rojas en Buenos Aires, se podría tantear una conjetura: tal vez el desinterés responda a que el autor de Hijo de ladrón representaba una parte consolidada de la tradición narrativa chilena, cuyas manifestaciones no habían suscitado hasta ese entonces la atención del campo cultural argentino. Como si el foco, o el punto de vista evocado en un principio, al menos en lo referido a la literatura chilena, estuviese puesto ante todo en lo producido por los escritores más jóvenes, o al menos, como veremos a continuación, en aquellas escrituras que llegaban precedidas por la promesa de lo nuevo.

\section{País de poetas}

Veinte poemas de amor y una canción desesperada fue el primer título de Pablo Neruda que la Editorial Losada publicó en Buenos Aires. En 1964, transcurridos veinte años de esa primera edición argentina, la casa editorial anunciaba haber vendido un millón de ejemplares del célebre poemario. A partir de esa reedición de Veinte poemas..., Losada se convirtió en una de las principales casas editoriales en las que Neruda fue acumulando sucesivas entregas ${ }^{15}$. Así, por ejemplo, hacia el fin de la década Losada publica en Buenos Aires La barcarola (1967), Las manos del día (1968) y Fin de mundo (1969). La presencia reiterada del vate chileno en las listas de novedades permite adelantar uno de los aspectos sobre los que discurre lo que sigue: Neruda era un personaje habitual para la prensa literaria porteña.

El mismo año de ese millón de ejemplares vendidos, la editorial de la Universidad de Buenos Aires (Eudeba) publica La cueca larga y otros poemas, una antología de Nicanor Parra preparada por Margarita Aguirre y Agustín Palazuelos ${ }^{16}$. Pero fue recién cinco años después, cuando Siglo XXI gestionó la importación de cien ejemplares del recién editado Obra gruesa, que Parra fue objeto de una atención especial por parte de la crítica local. Si bien la circulación de este libro había comenzado en Chile hacia junio de 1969, fue en septiembre de ese año cuando llegó a Buenos Aires. Su arribo a las librerías 
argentinas coincide con el reconocimiento oficial de Parra en Chile, pues el 16 de septiembre le otorgan el Premio Nacional de Literatura ${ }^{17}$.

Quizá la presencia más espectacular de Neruda en los medios escritos argentinos de 1969 sea la portada que le dedica el semanario Confirmado. Arriba de una foto de Neruda al aire libre, rodeado por tres perros, se lee lo siguiente: PABLO NERUDA ¿POR QUÉ NO SE SUICIDA? Al interior, una nota de Miguel Briante (1969a), por entonces secretario de redacción de la revista, da cuenta de una visita que este le hiciera al poeta en su casa de Isla Negra. En el paso de Briante por Chile, Antonio Skármeta había hecho las veces de guía y contacto con el mundo cultural ${ }^{18}$. El reportaje deja entrever varías críticas al estilo de vida de Neruda, y se centra menos en sus últimas entregas literarias que en su por entonces vigente campaña a la presidencia de Chile, apoyada por el Partido Comunista.

Entretanto, en Buenos Aires, una profusa recepción de su último libro, Fin de mundo, se había ensañado con el autor de Crepusculario. La producción literaria de Neruda es "cada vez más endeble y reiterada", se sugiere casi con suavidad en Análisis ("La ronquera" 1969: 53). Panorama sube un poco la apuesta: "el más olvidable de los prescindibles libros que Neruda ha venido escribiendo en esta década" ("Monumento" 1969: 76). Mientras que Señoras y Señores se despacha sin remilgos: "liróforo aburguesado, es ya un político liberal, uno de esos incendiarios comecuras que niegan a Dios sólo porque desean ocupar su sitio. De las furias y las penas que exaltó en 1934, le quedan las furias, con las cuales pretende vigorizar sus versos" ("El narcisista" 1969: 16). Solo la voz de Juan Gelman se alza para defender a Neruda desde las páginas de la revista Los Libros. Una reseña en versos de Fin de mundo, donde Gelman rechaza a los "pequeños criticantes" locales que se lanzan contra el gran poeta. En realidad, no habla del libro recién publicado, aunque, fiel al formato de la revista, su texto se anuncia como una reseña. El poema-reseña intercala versos de Fin de mundo y de Gelman, y en el ínterin clama por el poeta criticado: "Déjenlo en paz, hijos de puta" (1969: 7). Por último, cabe señalar que varias de las reseñas destacaron el poema dedicado a Oliverio Girondo (Neruda 1976: 59-64) ${ }^{19}$.

31 Por su parte, la llegada de Obra gruesa a las librerías argentinas también fue ampliamente cubierta por la prensa especializada. Publicado en Santiago por Editorial Universitaria, Obra gruesa incluye todos los libros publicados hasta ese entonces por Parra, con la excepción de Cancionero sin nombre, y agrega tres secciones de poemas hasta entonces inéditos. En líneas generales, la recepción del libro transita por apreciaciones diametralmente opuestas a las suscitadas por la última entrega de Neruda. Parra es entonces, aquel que viene a renovar la poesía chilena mediante "palabras despojadas de adornos", enarboladas "agresivamente para descargarlas como un mazazo sobre la retórica y los buenos modales de los sonetistas dominicales" (Salas 1969: 52). Por otro lado, el mismo Briante subraya que se trata de un poeta que reflexiona permanentemente sobre la validez de sus propios medios, lo que lo lleva a calificarlo de poeta de vanguardia, y a renglón seguido aclara que esto es así "si uno despoja a la palabra vanguardia de sus connotaciones meramente experimentalistas, vacías, de moda". Lo que también da lugar a su comprensión como un "poderoso aporte a la poesía joven del continente" ("Un legislador" 1969: 65) ${ }^{20}$. Más aun, y en sintonía con las urgencias de la época, se valora su poesía como un "arma de combate dispuesta al enfrentamiento real con las expresiones del mundo burgués", al tiempo que se ubica a la antipoesía como lugarteniente de la revolución y, por lo tanto, como "una forma de 
violencia expresiva y creadora", en suma, como "la única alternativa para salvar a la poesía" (Fuentes 1969: 7). En la revista SUR, Roberto Yahni también pondera el carácter revolucionario de la poesía de Parra, sin por ello apelar al costado político recién mencionado; subraya, en cambio, el carácter inclusivo de la "revolución antipoética" en cuanto a la amplitud de los mundos que incluye, y en esa línea ubica su novedad en la “equiparación de la poesía a la vida por medio de la palabra" (1969: 102)

En este marco, los artículos sobre la poesía de Parra rescatan algunas influencias -el folclor chileno, los beatniks, Char, Cendrars, Maiacovski, entre otros- y arriesgan algunas relaciones -i.e. el surrealismo, Macedonio, Vallejo. Aunque si se trata de nombres y de alusiones a otras escrituras, sobresale la insistente y porfiada contraposición con Neruda como estrategia de presentación de las particularidades de Parra. Una breve detención en esta circunstancia hará las veces de cierre de este apartado.

En los distintos comentarios hechos sobre Obra gruesa, el nombre de Neruda servía como moneda de cambio para reiterar su calificación de vetusto, pero también, y acaso sea lo más interesante, permitía refrendar el interés del campo literario argentino por todo aquello que portara los rasgos de lo nuevo en sus distintas modulaciones, vale decir, lo provocativo, lo radical, lo vanguardista, lo revolucionario. Del otro lado, quedaba relegada "la decadencia de Neruda, que tal vez un Premio Nobel terminará por corroborar" ("Un campeón" 1969: 18). Bajo esta óptica, tal vez un suelto de la sección "GUíA de Libros" del semanario Confirmado, donde se consignaban las características más salientes de algunas novedades en el mercado de libros, discos, films, exposiciones, obras de teatro, etc., sintetice esta perspectiva de forma ejemplar. Entonces, copio el texto íntegro de la breve presentación de Obra gruesa:

Que el prolífico, publicitado Neruda, le haya ido creciendo silenciosamente un rival que ya anda borrándolo, que ya tiene mucho más que ver con el futuro, no es asunto que deba dejarse de lado. Una antología en que Parra reúne lo mejor de su poesía -o antipoesía- es la mejor prueba ("GUÍA" 1969: 3).

De este modo, la división de aguas parece asentarse en la inclinación hacia el futuro con que desde ese presente argentino se leía la escritura de Parra ${ }^{21}$. Pablo Neruda, que en algunas reseñas sobre la poesía de Parra es puesto en serie con de Rokha, Huidobro o Mistral, representa el pasado en su versión más anquilosada. Parra, en cambio, ofrece la superficie para encarnar los valores de la renovación que estaban a la orden del día en el campo literario argentino.

\section{El chileno más leído}

Sin duda, el autor chileno que más atención concitó en la prensa porteña de 1969 fue Antonio Skármeta con su libro de cuentos Desnudo en el tejado, publicado por la editorial Sudamericana en su colección El Espejo ${ }^{22}$. Para dar cuenta de ello rescato, en primer lugar, algunas observaciones que se hicieron a propósito de su premiado libro de cuentos. En segundo lugar, me detendré en algunos detalles del comentario aparecido en la revista Los Libros, desde cuyas páginas se impulsaba una renovación de la crítica literaria a tono con las radicalizaciones del momento: políticas, teóricas y estéticas.

Con presencia en los grandes semanarios de circulación nacional y en otros medios escritos -Análisis; Confirmado; Los Libros; Panorama; Primera Plana; Siete días; Uno por $U n 0^{23}-$, la recepción del libro de Skármeta no sólo permite mostrar de modo concreto el 
interés que suscitaban en Buenos Aires las nuevas manifestaciones literarias del subcontinente, también permite llamar la atención sobre las altas exigencias y expectativas con que estas manifestaciones eran recibidas.

Tratándose de un libro de cuentos, las reseñas de los semanarios se organizan de manera relativamente estándar: una breve semblanza biográfica es seguida de observaciones generales sobre el libro, las que a su vez son sucedidas por anotaciones centradas en las particularidades de los cuentos. En este marco, se repiten los comentarios que destacan la presencia del humor en los distintos relatos y los que valoran el despliegue técnico de las formas de narrar ensayadas a lo largo del libro. También se suceden las menciones al jazz, a la beat generation y, en menor medida, a la influencia del cine en sus modos de narrar. En casi todas las notas no se ahorran elogios para la joven promesa de las letras chilenas. Y si bien tanto en la reseña de Panorama como en la de Uno por Uno hay abiertos reparos, por tratarse de "un escritor que todavía no ha dejado atrás su época de tanteos" ("Ejercicios" 1969: 65), o por sus "ludismos esteticistas" (Osnajanski 1969: 2), en ambas ocasiones no dejan de señalar, respectivamente, su notable "virtuosismo" y "talento". Dentro de este panorama, sobresale un elemento que ya fue consignado al principio de este artículo: cuando se alude a la literatura chilena se desliza la opinión de que se trata de una tradición carente de grandes narradores. Como si todo el andamiaje de elogios elaborado a propósito de Desnudo en el tejado estuviera montado gracias al baldío que lo precede: "orfandad de narradores", se dice en Primera Plana; "empobrecida narrativa", se apunta en Siete días. Aquí vale la pena recordar lo dicho en un principio, en este contexto interesa menos la pertinencia de lo dicho que la posición desde la que se dice tal o cual cosa sobre la literatura chilena.

Para cerrar este apartado, voy a detenerme en el comentario que publicara Nicolás Rosa sobre el libro de Skármeta en la revista Los Libros. Rosa es tal vez el miembro más emblemático de esta primera etapa de una revista que, como es sabido, marca un hito en la historia de la literatura argentina. Este lugar central de Rosa no responde tanto a su marcada filiación estructuralista, compartida con otros miembros de la revista, sino sobre todo a que él es quien de modo más insistente y sofisticado intenta formular desde allí una adhesión a la revolución política que se creía en ciernes (Walker 2019). Rosa organiza su interrogación por las posibilidades de una nueva crítica (1969a) a partir de la capacidad de leer en la literatura sus "significaciones verdaderamente revolucionarias" (1969b: 4). De forma sintética, su posición crítica se puede comprender como una negociación permanente entre el ideal científico del estructuralismo francés y el ideal utópico de la izquierda revolucionaria. Con este arsenal teórico y con esa ambición por refundar la crítica argentina, el joven Nicolás Rosa lee al joven Antonio Skármeta.

En el artículo dedicado a Desnudo..., Rosa despliega una aguda reflexión sobre la libertad de la literatura y eso que desde el título llama "la felicidad de la letra". Los distintos relatos son definidos de entrada como "convincentes formulaciones de la adolescencia" (1969c: 12), mientras que su vocación de libertad se atribuye a la construcción de monólogos que conjugan la palabra hablada y la música. La ambición estética de estos cuentos, acota Rosa, está muy por encima de las experiencias narrativas contemporáneas. Se trata, en suma, de "reinventar a través de las palabras el ritmo de la música, y a través de ella, el hecho poético", lo que es anotado a cuenta de ciertas "transgresiones perpetradas contra la narración tradicional" (1969c: 12). En este 
sentido, Rosa ubica a lo hecho por los beats con el jazz como el antecedente inmediato y lógico de Skármeta. Y a continuación, afirma que las particularidades del chileno se juegan en "una motivación más profunda y personal que se conecta con la creación de un ritmo respiratorio de la prosa" (1969c: 12). Esta búsqueda de un ritmo respiratorio, poético, de la prosa se asienta en una permanente ascensión de los personajes, que se desenvuelve con tintes místicos y eróticos. La "libertad de la escritura" está dada, entonces, por una suerte de "paráfrasis secular de la ascesis mística" (1969c: 12).

Ahora bien, la intensidad de estas adolescencias narradas por Skármeta, su aspiración a confundirse con la música y las transgresiones que de allí derivan para con las formas de narrar, son puestas en serie no ya con la literatura chilena sino con la de otros jóvenes ilustres que escriben en la misma lengua. Todas las características que Rosa atribuye a Skármeta son pasadas por el tamiz de la influencia del cine, lo que le permite trazar algunas analogías entre sus textos y los de Guillermo Cabrera Infante, Manuel Puig y Néstor Sánchez. Todos son escritores jóvenes que, ya en 1969, marcaban una distancia con el boom latinoamericano y eran reconocidos como los grandes escritores de la literatura por venir. Sus escrituras, afirma Rosa, están signadas "por una infancia alimentada con la esencia pura de la impostura imaginaria: el cine", y con esto marca un fuerte contraste con la literatura de sus predecesores, quienes "pasaron de la realidad a la ficción sin mediaciones" (1969c: 13). Desde luego, llama la atención este desprecio por la influencia del cine en la literatura bajo la pluma de un intelectual que se proponía renovar la práctica crítica, pero lo que resulta más significativo es que su representación del cine parece entrar en serie con una reivindicación del realismo como única vía para la producción literaria ${ }^{24}$. Tal vez, la última frase del artículo nos ayude a comprender mejor el asunto:

Una manera [la de Skármeta] de contar la experiencia y no de recrear la literatura, pero al mismo tiempo verla atrapada en las palabras y las imágenes puesto que recrear esas palabras es recrear el cine de la infancia, entregarse a la otra pantalla, todo es puro biógrafo, la literatura como la vida, una ficción, un cuento, pero un cuento maravilloso, donde el narrador elabora -irónica pero gustosamente- su propia ascesis de liberación, de desprendimiento de los crueles mitos de la adolescencia para sentarse olímpicamente desnudo en el tejado de las palabras (1969c: 13) ${ }^{25}$.

Rosa valora que los cuentos de Desnudo... no se contenten con recrear la literatura, que vayan más allá, que aspiren a dar cuenta de una experiencia, pero lamenta que esa experiencia no ofrezca otra cosa que el pedestal de palabras e imágenes, que es consignado como un encierro. Se posiciona en contra de esa pantalla, pues todo indica que la lee como una mediación que introduce irrealidad en la producción literaria, es decir, como una permanente "negación de la realidad" (1969c: 13) en la que se vive ${ }^{26}$. La liberación falla por esta vía, pues se engaña y queda entrampada en las palabras o en la pantalla, como sea, es incapaz de vérselas con la realidad y, por lo mismo, está lejos de esos sentidos verdaderamente revolucionarios añorados por el crítico.

\section{Contra la literatura chilena}

42 En un texto dedicado a reflexionar sobre las condiciones de posibilidad de la literatura nacional, César Aira recurre a Amalia de José Mármol, "la primera novela argentina" (2012: 34), para ensayar sentidos sobre este asunto tan espinoso, tan visitado. Para ello, parte de una hipótesis de apariencia sencilla: "una literatura se hace nacional, y es asumida como propia por los lectores de una nación, cuando se puede hablar mal de 
ella, no cuando se puede hablar bien" (2012: 25). La idea evoca a su vez esa regla tácita de la vida social que dicta que cada quien puede hablar mal de sus familiares o de sus connacionales, pero que ese derecho es intransferible a quienes no lo son. Hablar mal del otro, afirma Aira, "es un derecho que confirma la propiedad, la intimidad, el cariño y hasta el orgullo" (2012: 25).

43 A vuelo de pájaro, es posible plantear que la hipótesis de Aira podría servir para comprender algunos de los episodios revisados aquí, en particular, los repetidos menosprecios para con la poesía de Neruda, o bien, el minucioso desglose con que Rosa impugna la propuesta literaria de Skármeta. Sin embargo, antes cabría llamar la atención sobre algunas omisiones -incluso errores- en las que incurren los comentarios hechos sobre la literatura chilena que circuló en Buenos Aires en 1969. Vale decir, quizá no baste con hablar mal de tal o cual libro para integrarlo a una literatura nacional. Como sea, el aserto de Aira hará las veces de guía para estas breves palabras finales.

Hablar mal no alcanza, si cuando se elabora un repaso detallado de todos los cuentos de Desnudo en el tejado el lector de la reseña no se entera, por ejemplo, que el cuento "Una vuelta en el aire" ficcionaliza los últimos días de Gabriela Mistral, de quien, además, leemos dos de sus versos en el epígrafe del cuento. Dentro de las numerosas reseñas de las que fue objeto el libro de Skármeta, si bien en casi todas se alude puntualmente al cuento, todo indica que los reseñistas, siempre prestos al name-dropping de las influencias, no vieron la evidente alusión y el consecuente homenaje a Mistral de ese cuento, quien incluso es parafraseada en algunos pasajes ${ }^{27}$. Hablar mal no alcanza, si cuando se pondera a Parra o cuando se desconfía de Neruda se escribe equivocadamente el nom de plume de Carlos Díaz Loyola, es "Pablo de Rocka" acá, es "Pablo de Roca" allá (Salas 1969: 52; Briante 1969: 36). Hablar mal no alcanza, si al señalar la orfandad de la narrativa chilena, no se matiza con algún nombre reciente o no tan reciente que venga a dar algún otro soporte al juicio general.

De todos modos y valga la insistencia, no se trata aquí de verificar el grado de corrección con que se presentan las críticas sobre la literatura chilena. Más bien, intenté realizar un recorrido que acentuara la posición de lectura ante los textos que, como se vio, está hecha de desconfianza ante la calidad de lo que se lee, pero también de un alto grado de exigencia. En otras palabras, la circulación y la recepción de los libros chilenos dan cuenta de una marcada dimensión especular que parece estar en la base de estas presencias de la literatura chilena en Buenos Aires.

No se trata entonces, de que los malos y los buenos juicios revisados consigan argentinizar los textos comentados, volverlos literatura nacional. En cambio, la maledicencia da a ver una manera en que lo nacional, lo argentino, se despliega como plataforma de lectura. No sólo por hablar mal, claro, sino por la manera en que ese modo de dar a ver una lectura permite avizorar las valoraciones y sentidos con que se aborda el fenómeno literario. Y es en este punto que resulta esclarecedor el designio de Aira: hablar mal es, aquí, una estrategia de lectura que incluye la apropiación de lo leído, que mediante el gesto de hacerlo próximo y conocido -decir, por ejemplo, que la narrativa chilena está huérfana de grandes exponentes implica, al menos, un enunciado bajo el semblante de un conocimiento acabado- lo procesa, lo interroga, lo festeja, lo desdeña y, por ese expediente, va tanteando sus sentidos.

Ahora bien, todo el recorrido muestra distintas inflexiones de esa estrategia de apropiación lectora. Como si esa intensidad de lectura precisara apropiarse de los textos para desplegar sus rasgos más característicos. En otros términos, la posición de 
lectura argentina ante estos materiales parte de un gesto de aproximación que difumina las fronteras nacionales, que fagocita las letras del país vecino para exigirles lo mismo que le exige a las propias: novedad, transgresión, juventud, vanguardia, nada de repetición ni monumentos al pasado. Para los nuevos mundos que confluyen en Argentina hacia el final de esa década -la nueva clase media liberal y la nueva izquierda-, la literatura importa en la medida que parece ofrecer un remedo de sus respectivas expectativas de futuro.

Por último, vale la pena hacer un breve repaso de los episodios bajo la perspectiva habilitada por la ocurrencia de Aira. Hay, por un lado, un marcado interés por las nuevas producciones, ya sea por la perspectiva de los jóvenes sobre la actualidad de la literatura chilena, como lo demuestra la antología publicada por Jorge Álvarez, ya sea por los estandartes de lo nuevo con que se comprende la antipoesía de Nicanor Parra, lo que permite acentuar el costado añejo del gran poeta Neruda (quien a pesar de todo seguía publicando a un ritmo frenético), ya sea por el interés con que es leído el libro de cuentos de Antonio Skármeta, muy luego puesto en el pedestal de gran narrador chileno, muy luego agrupado dentro de la renovación -¿reaccionaria?- de la novísima literatura latinoamericana. En contrapartida, brilla la indiferencia que le es ofrecida a uno de los grandes escritores chilenos del siglo XX, Manuel Rojas, como si el interés por la literatura chilena tuviera fecha de caducidad, vale decir, como si la atención prodigada a una literatura vecina no fuera capaz de trasladarse hacia el pasado reciente, ni mucho menos hacia otras épocas. Algo de esta circunstancia se repite hoy en día, aunque con muchos matices y tecnologías diferentes de por medio, donde el nutrido intercambio de libros no hace más que crecer en lo relativo a las producciones más recientes, pero eso no alcanza para volver la mirada hacia los distintos pasados de la literatura chilena.

\section{BIBLIOGRAFÍA}

AA.VV., Pidamos peras a Jorge Álvarez, Biblioteca Nacional Mariano Moreno. Web. Consultado el 18 de septiembre de 2021.

Aira, César, “Amalia”, Cuadernos Hispanoamericanos n 743, 2012, p. 25-35.

Anónimo, “Chilenos. El Verbo y Los Beatles”, Análisis n 424, 29/04/1969, p. 58.

Anónimo, "Ejercicios de un narrador. Reseña Antonio Skármeta, Desnudo en el tejado, Sudamericana", Panorama n ${ }^{\circ}$ 125, 18/09/1969, p. 65.

Anónimo, "El narcisista inofensivo. Reseña Pablo Neruda, Fin de mundo, Losada", Señoras y Señores $\mathrm{n}^{\circ} 1,26 / 09 / 1969$, p. 16.

Anónimo, "GUÍA de Libros. Sobre Nicanor Parra, Obra gruesa, Universitaria", Confirmado $\mathrm{n}^{\circ} 222$, 17/09/1969, p. 3.

Anónimo, "GUÍA de Libros. Sobre Antonio Skármeta, Desnudo en el tejado, Sudamericana”, Confirmado $\mathrm{n}^{\circ} 225,08 / 10 / 1969$, p. 4. 
Anónimo, "La ronquera del bardo. Reseña Pablo Neruda, Fin de mundo, Losada", Análisis n ${ }^{\circ} 443$, 09/09/1969, p. 53.

Anónimo, “La sumisión del lenguaje”, Análisis n 442, 02/07/1969, p. 72-73.

Anónimo, "Monumento con apéndice suprimible. Reseña Pablo Neruda, Fin de mundo, Losada", Panorama $\mathrm{n}^{\circ}$ 124, 09/09, p. 76.

Anónimo, "Novedades", Confirmado n² 227, 22/10/1969, p. 62.

Anónimo, "Primeras ediciones de las obras de Pablo Neruda", Neruda, Universidad de Chile. Web. Consultado el 18 de septiembre de 2021.

Anónimo, "Reseña Antonio Skármeta, Desnudo en el tejado, Sudamericana", Siete días ilustrados n ${ }^{\circ}$ 120, 25/08/1969, p. 66.

Anónimo, "Skármeta o el fervor. Entrevista a Antonio Skarmeta", Primera Plana nº 325, 18/03/1969, p. 60.

Anónimo, “Textos de Primera Plana. Adelanto de Antonio Skármeta, Desnudo en el tejado”, Primera Plana $\mathrm{n}^{\circ} 325,18 / 03 / 1969$, p. 64-65.

Anónimo, "Un campeón de la antisolemnidad. Reseña Nicanor Parra, Obra gruesa, Universitaria", Señoras y Señores nº 1, 26/09/1969, p. 18-9.

Anónimo, “Un legislador no reconocido. Reseña Nicanor Parra, Obra gruesa, Universitaria”, Panorama no 127, 30/09/1969, p. 64-65.

Apir, "Vitrina literaria. Tiempo de arañas", La Provincia, 1986, p. 3. Web. Consultado el 30 de mayo de 2021.

Binns, Niall, "Notas", Parra, Nicanor, Obras completas \& algo +, Santiago, Galaxia Gutemberg, p. 909-1050.

Briante, Miguel, “Canto general por Neruda”, Desde este mundo. Antología periodística 1968-1995, 2004, p. 218-221.

---, "Hoy: el chileno que se olvidaron en el techo. Entrevista a Antonio Skarmeta", Confirmado n ${ }^{\circ}$ $217,14 / 08 / 1969$, p, 50-51.

---, "Sobre poesía y verdad. Reseña Nicanor Parra, Obra gruesa, Universitaria", Confirmado n 222 , 17/09/1969b, p. 50.

---, “Pablo Neruda ¿por qué no se suicida?”, Confirmado n² 235, 17/12/1969c, p. 34-36.

---, "Libros 1969: Memoria y Balance", Confirmado n² 237, 31/12/1969d, p. 44-47.

Casañas, Inés y Fornet, Premio Casa de las Américas. Memoria 1960-2020, La Habana, Fondo Editorial Casa de las Américas, 2021.

Cáceres, Yenny, Los años chilenos de Raúl Ruiz, Santiago, Catalonia-UDP, 2019.

Concha, Jaime, "Manuel Rojas. El otro tiempo perdido", Leer a contraluz. Estudios sobre narrativa chilena. De Blest Gana a Varas y Bolaño, Santiago, Universidad Alberto Hurtado, p. 223-44.

De Diego, José Luis, "La literatura latinoamericana en el proyecto editorial de Losada", Actas III Congreso Internacional de Literatura y Cultura Española Contemporánea, 2014. Web. Consultado el 30 de mayo de 2021.

---, "La edición de literatura en la Argentina de fines de los sesenta", Los autores no escriben libros, Buenos Aires, Ampersand, p. 147-184. 
Dujovne, Alejandro, "La diáspora en imprenta. Actores, tramas y espacios del libro judío en Buenos Aires, 1910-1960”, Revista del Museo de Antropología nº 6, 2013, Universidad Nacional de Córdoba, p. 119-132.

Espinoza, Enrique, Manuel Rojas, narrador (1896-1973), Buenos Aires, Babel, 1976. Web. Consultado el 29 de mayo de 2021.

Faúndez, Pablo, El Premio Nacional de Literatura en Chile: de la construcción de una importancia, Valparaiso: Ediciones Universitarias, 2020.

Fuentes, Osvaldo, "Parra con todo", Uno por Uno n 3, 1969, p. 7-8.

Fuenzalida, Daniel (comp.), "El escritor chileno Manuel Rojas”, Conversaciones con Manuel Rojas. Entrevistas 1928-1972, Santiago, Zig-Zag, p. 187-196.

García Lupo, Rogelio y Shakespear, Ronald, “La librería de la calle Talcahuano 485”, Jornada Revisitar los 60. La experiencia de Jorge Álvarez, 23/03/2012, Biblioteca Nacional Argentina, Youtube. Web. Consultado el 18 de septiembre de 2021.

Gelman, Juan, “En la cintura de este libro. Reseña Pablo Neruda, Fin de mundo, Losada”, Los Libros $\mathrm{n}^{\circ}$ 5, p. 6-7.

Giaconi, Claudio, “Una experiencia literaria”, Revista Atenea n 380-381, 1958, Universidad de Concepción, p. 282-289.

Girondo, Oliverio, Obra Completa, edición crítica dirigida por Raúl Antelo, Madrid, ALCCA XX.

Godoy, Eduardo, La generación del 50 en Chile. Historia de un movimiento literario, Santiago, La Noria, 1991.

---, "La generación del 50 en Chile: razones y efectos de una polémica", América: Cahiers du CRICCAL n² 21, 1998, p. 369-375.

Goic, Cedomil, La novela chilena. Los mitos degradados, Santiago, Universitaria, 1997.

Guzmán, Nicomedes (comp.), Autorretrato de Chile, Santiago, Zig-Zag, 1974.

Laforucade, Enrique (comp.), Antología del nuevo cuento chileno, Santiago, Zig-Zag, 1954.

Larraz, Fernando, Editores y editoriales del exilio republicano de 1939, Sevilla, Renacimiento, 2018.

Lastra, Pedro, "Introducción a la poesía de Nicanor Parra", Revista del Pacífico n 5, 1968,

Universidad de Chile. Valparaíso. Web. Consultado el 18 de septiembre de 2021.

Mahieu, Agustín, “Raúl Ruiz: un chilote vence en Locarno”, Confirmado n 227, 22/10/1969, p. 67.

Moretic, Yerko (comp.), El nuevo cuento realista chileno, Santiago: Universitaria, 1962.

Neruda, Pablo, Fin de mundo, Buenos Aires, Losada, 1976.

Osses, Darío, "La ciudad y sus tiempos en la obra narrativa de Guillermo Atías", Anales de literatura chilena $\mathrm{n}^{\circ}$ 27, Universidad Católica de Chile, p. 181-191, 2017.

Osnajanski, Norma, “Los libros Uno por Uno”, Uno por uno n³, 1969, p. 2.

Parra, Nicanor, La cueca larga y otros poemas, Buenos Aires, Eudeba, 1964.

---, Obra gruesa, Santiago, Universitaria, 1969.

Podlubne, Judith, “"La pérdida de la inocencia». Los primeros lectores de Barthes en la crítica literaria argentina", Revista Iberoamericana n ${ }^{\circ} 261$, octubre 2017, Universidad de Pittsburgh Press, 899-921. Web. Consultado el 29 de mayo de 2021. 
Quijada, Rodrigo (comp.), Crónicas de Chile, Jorge Álvarez, Buenos Aires, 1968.

Rojas, Manuel, Viaje al país de los profetas, Buenos Aires, Zlotopioro, 1969.

Rosa, Nicolás, “Nueva novela latinoamericana. ¿Nueva crítica?”, Los Libros nº 1, 1969a. p. 6-8.

---, "La crítica como metáfora. Sobre Severo Sarduy, Escrito en un cuerpo, Sudamericana", Los Libros $\mathrm{n}^{\circ} 2,1969$ b. p. 4-5.

---, "La felicidad de la letra. Sobre Antonio Skármeta, Desnudo en el tejado, Sudamericana", Los Libros $\mathrm{n}^{\circ} 4,1969$ c. p. 12-13.

Salas, Hugo, "El albañil y el muro. Reseña Nicanor Parra, Obra gruesa, Universitaria", Análisis n ${ }^{\circ}$ 446, 30/09/1969, p. 52-53.

Walker, Carlos, "La moda al día: estructuralismo argentino 1969”, Revista Landa vol. 7, n² 2, 2019, p. 250-283. Web. Consultado el 28 de mayo de 2021.

Woolf, Virginia, "Las cartas de Henry James", Genio y tinta, Lumen, Santiago, 2021, p. 67-80.

Yahni, Roberto, “Reseña Nicanor Parra, Obra gruesa, Universitaria”, SUR n 321, noviembre 1969, p. 101-103.

Yañez, Flora, Antología del cuento chileno moderno, Santiago, Del Pacífico, 1958.

\section{NOTAS}

1. Si se consideran los otros libros premiados en las distintas categorías del premio en 1969, o incluso en los años cercanos, no se verifica nada cercano a una correlación entre los títulos premiados y el grado de circulación de ellos en los medios escritos argentinos. Para acceder a la lista de los premiados en la historia del premio y al dictamen que consagró a Skármeta, ver Casañas y Formet 2021.

2. En lo que sigue se recurre a muchos artículos sin firma, Anónimos, como era costumbre en los semanarios de información. Los paréntesis donde se consigne una referencia a este tipo de texto seguirán el siguiente esquema: ("Primera palabra del título del artículo" año: página). Los datos bibliográficos completos serán consignados en la sección “Anónimo" de la bibliografía

3. Este trabajo es un desprendimiento de una investigación más amplia centrada en un año específico de la literatura argentina: 1969.

4. Todo el detalle de la información sobre la producción de la editorial Jorge Álvarez y la del sello musical Mandioca se puede encontrar en línea, en el catálogo de la exposición Pidamos peras a Jorge Álvarez, realizada en la Biblioteca Nacional en el año 2012 (AA.VV. 2012).

5. Para una caracterización detallada de esta autoreivindicada generación literaria chilena, véase el estudio de Eduardo Godoy (1991) y el "Exordio" con que Enrique Lafourcade abre la Antologia del nuevo cuento chileno.

6. Teillier, Ossa, y de nuevo Lihn, integran la otra célebre antología de cuentos que se propusiera como alternativa estética y política a la de Lafourcade (ver Moretic 1962). Mientras que Atías, Blanco y Giaconi forman parte de una tercera antología de cuentos, la que si bien fue una propuesta de alcance temporal más amplio y menos polémico que las dos ya mencionadas, no por ello dejó de servir como espacio de consagración en el marco de la literatura nacional (ver Yañez 1958).

7. “"Gato en el camino» es altamente revelador de la postura audaz asumida ya en un momento juvenil por Parra frente a la materia literaria, y responde a la más decidida voluntad de ruptura con la tradición inmediata. El absurdo, la inconexión y el humor son las notas resaltantes del cuento. La historia y las rápidas aventuras de ese gato extraviado, requerido a veces, rechazado 
en otras ocasiones -son las más-, y finalmente solo y libre por los caminos, prefiguran, en más de un sentido, la orientación futura del antipoeta" (Lastra 1968).

8. El panorama involuntario de la tradición narrativa chilena que resulta de estas pocas líneas bien podría servir para afirmar un rasgo singular de la literatura chilena que, tentativamente, podría marcar una diferencia con la literatura argentina: Chile, país de generaciones y de antologías. Pero sobre todo nos permite subrayar que la confección de una antología como la que ofrecen las Crónicas de Chile no es para nada un mero gesto recopilatorio. Se entiende entonces, que Quijada aprovechara su “Advertencia..." para reivindicar una suerte de montaje de autor como estrategia de presentación del libro.

9. Las aprehensiones son del propio Rojas (1969: 14-15). A pesar de ello, no queda claro porqué su defensa de los judíos en la URSS hacía, a sus ojos, poco probable que lo invitaran a Israel.

10. La entrevista, realizada por Sonia Quintana, se publica originalmente en la revista En Viaje, en el $n^{\circ} 426$ correspondiente a la edición de abril de 1969.

11. Fundada en 1948 por los hermanos Jacobo y David Zlotopioro, llegados desde Polonia en 1920 , y vigente al menos hasta el fallecimiento de Alberto en 2017, hijo de David, los Talleres Gráficos no sólo fueron una imprenta clave para las pequeñas editoriales nacionales de los sesenta, también jugaron un papel decisivo en la impresión de textos en yiddish y, por lo tanto, en la difusión de la tradición judía en Buenos Aires (Dujovne 2013).

12. Tal y como lo detalla el mismo Espinoza, en el colofón de su libro sobre Rojas, la biografía fue una iniciativa de José Bianco para una colección de Centro Editor de América Latina, pero no llegó a publicarse por ese sello y recién se publicó en 1976 en Ediciones Babel, dirigidas por el mismo Espinoza (1976: 55). El libro de Sudamericana fue editado en 1970 y en 2016 reeditado en Chile por la Universidad Alberto Hurtado.

13. También hay algunas palabras en el número 4 de Los Libros, dentro de la lista de publicaciones que cierra el número, en la sección que estaba a cargo de Ricardo Piglia: "Un relato de viaje donde el autor de Hijo de ladrón, narra una visita a Israel realizada en 1969” (29).

14. Estas características le permitieron a Jaime Concha ponderar la importancia de este libro en la obra de Rojas: "Decimos esto para precavernos de lo que vamos a señalar más adelante, en el curso de este mismo trabajo, respecto a Viaje al país de los profetas (1969), una de las últimas publicaciones de Rojas y a la que siempre hemos concedido gran relevancia para comprender los valores e impulsos espirituales que habitaron su obra" (2011: 224).

15. Agrego un dato, entre tantos, para dar una idea de la importancia de la editorial argentina para el poeta chileno: entre 1947 y su muerte, Losada publicó diecisiete ediciones prínceps de Neruda (Anónimo, "Primeras ediciones...").

16. Ambos son escritores chilenos. En este contexto, vale la pena señalar que ese mismo año Margarita Aguirre publicó en Eudeba Genio y figura de Pablo Neruda. Aguirre fue una destacada narradora, sus cuentos también fueron incluidos en las antologías de Lafourcade y Moretic mencionadas más arriba.

17. Feliz coincidencia para la empresa que se decidió a importar el libro, pero para nada decisiva. Las primeras reseñas de Obra gruesa, con el libro ya circulando en Buenos Aires, datan de principios de septiembre.

18. Muchos años después, Briante evocó varios detalles de su paso por Chile y se explayó sobre el curioso título de la nota de Confirmado: "Íbamos a hacerle un reportaje a Pablo Neruda pero yo tenía una consigna que era [...] un prejuicio: si varios poetas chilenos se habían suicidado, por qué él, Neruda, que se proclamaba comunista a ultranza y escribía versos torturados, vivía tan cómodo y tan como un alto burgués" (2004: 220).

19. El mismo poema fue incluido en la Obra Completa de Girondo editada por Raúl Antelo (1999: 769-772).

20. Joven, es aquí un valor literario antes que una cuestión etaria. Parra ya cuenta con 55 años y, de hecho, a pocos días de haber recibido el Premio Nacional de Literatura propone que el 
galardón sea entregado en el futuro como estímulo a las y los escritores jóvenes, antes que a los viejos como él (cit. en Faúndez 2020: 177).

21. Desde luego, esta oposición estereotipada entre Parra y Neruda resulta más representativa de la circulación de la poesía chilena en Buenos Aires que de los problemas y variedades con los que se desenvolvía la poesía chilena en ese entonces. Con todo, anoto tres episodios que permiten avizorar la complejidad de la relación entre Neruda y Parra. 1) La primera edición de Poemas \& Antipoemas (1954) aparece con una elogiosa nota de Neruda en la cubierta del libro; 2) En 1962 Parra toma a su cargo el discurso del homenaje a Neruda que le ofrece la Universidad de Chile al declararlo Miembro Académico; 3) Desde 1967, Ignacio Valente contribuye a la consolidación de la obra de Parra como contradiscurso al nerudismo "oficial" (Binns, en Parra 2006: 911, 1036-1038, 960).

22. La colección El Espejo es presentada en el Catálogo General de Sudamericana impreso en 1969 de este modo: "una nueva colección que hace especial hincapié en los cada vez más apreciados autores latinoamericanos". De modo tentativo se puede datar su existencia entre 1965 y 1983. Si bien esta colección publicó ese mismo año títulos imprescindibles para la literatura argentina Boquitas pintadas; Cicatrices; Los suicidas-, todo indica que operaba más como rótulo que como conjunto con características propias. En Sudamericana, dirigida en ese entonces por Francisco Porrúa, "a diferencia de Losada y Emecé, apenas se concibieron colecciones editoriales concebidas como tales, con formato uniforme y dirección única de un experto" (Larraz 2018: 91). La cita del Catálogo y las puntualizaciones siguientes se las debo a la generosidad de José Luis de Diego.

23. En lo que sigue no hago alusión directa a todas estas reseñas, pero ellas están consignadas en la bibliografía.

24. Lo que, para cualquiera que revise los textos de Rosa del período, está muy lejos de sus postulados críticos.

25. Cursivas en el original.

26. En la misma línea, Rosa leerá los ensayos de Severo Sarduy, en el número 2 de Los Libros, sobre los que deplorará el exceso de juegos fonemáticos y la confianza en la producción de sin sentido bajo este designio: "su crítica elabora un lenguaje paralelo [...] que estigmatiza de irrealidad a todos los niveles del discurso” (1969b: 4). El subrayado es mío.

27. "la carne de la vieja sabía ser naranja, paloma, miga para las aves que se le epifanizaban en el regazo, un lecho para abrazar el mundo, hasta el país que no existe, país de la ausencia que es más ligero que ángel" (Skármeta 1969: 81)

\section{RESÚMENES}

En el marco de una investigación dedicada al campo literario argentino de 1969, se examinan episodios vinculados a la circulación de la literatura chilena en Buenos Aires. En particular, el artículo se detiene en una antología de narrativa chilena de la editorial Jorge Álvarez, en la publicación de un libro de Manuel Rojas, en los variopintos comentarios hechos a propósito de las obras más recientes de Pablo Neruda y Nicanor Parra, y en la importante recepción crítica de la que fue objeto Desnudo en el tejado de Antonio Skármeta. De este modo, se presenta un panorama de la presencia de la literatura chilena en Buenos Aires a fines de la década del sesenta. Al mismo tiempo, la circulación y la recepción crítica de los textos pertenecientes a la literatura chilena 
conforman un repertorio de manifestaciones heterogéneas que permiten dar cuenta de características específicas del campo literario argentino del período.

Dans le cadre d'une recherche plus vaste sur le champ littéraire Argentin de 1969, nous examinons des événements liés á la circulation de la littérature chilienne à Buenos Aires. L'article analyse, en particulier, la composition d'une anthologie de récits chiliens publié par la maison d'édition Jorge Álvarez; la publication d'un livre de Manuel Rojas ; les commentaires variés qui ont été fait sur les livres les plus récents de Pablo Neruda et Nicanor Parra; l'importante réception critique de Desnudo en el tejado de Antonio Skármeta. Ainsi, nous présentons un panorama de la présence de la littérature chilienne à Buenos Aires à la fin des années 1960. En même temps, la circulation et la réception critique de ces textes forment un répertoire de manifestations hétérogènes qui nous permettent de rendre compte des caractéristiques spécifiques du champ littéraire argentin de l'époque.

As part of a research dedicated to the Argentine literary field in 1969, we examine a series of events corresponding to the circulation of Chilean literature in Buenos Aires. In particular, this paper focuses on an anthology of Chilean narrative published by Jorge Alvarez press; on the publication of a book by Manuel Rojas; on the varied comments made on the most recent books by Pablo Neruda and Nicanor Parra; and on the important critical reception of Antonio Skármeta's Desnudo en el tejado. In this way, we propose a panorama of the presence of Chilean literature in Buenos Aires at the end of the 1960s. At the same time, the circulation and critical reception of these texts form a repertoire of heterogeneous manifestations which allows us to account for specific characteristics of the Argentine literary field of the period.

\section{ÍNDICE}

Mots-clés: 1969, critique littéraire Argentine, littérature Chilienne, Antonio Skármeta, Nicolás Rosa

Keywords: 1969, Argentine literary criticism, Chilean literature, Antonio Skármeta, Nicolás Rosa Palabras claves: 1969, crítica literaria argentina, literatura chilena, Antonio Skármeta, Nicolás Rosa

\section{AUTOR}

\section{CARLOS WALKER}

Investigador CONICET - Instituto de Literatura Hispanoamericana, UBA

carloswalker8@gmail.com 